\title{
An Epidemiological Study Of Mechanical Health Hazards Amongst Agricultural Workers In Rural India
}

\begin{abstract}
:
Background: Agricultural work is subject to the health risks inherent to a rural environment and at the same time to those deriving from the specific work process involved. India being a country of agriculture, majority of its population is engaged in agriculture based activities in a varied manner either directly or indirectly. This sector of activity being most unorganized, very little attention has been given to the occupational health problems of these workers; though the need of investigation and intervention towards these problems has repeatedly been mentioned. Objective: 1)To find out the demographic distribution of agriculture related mechanical health hazards 2)To find out the magnitude of agriculture related mechanical health hazards 3) To find out the protective measures being used by the agricultural workers for the prevention of mechanical health hazards.4) To give the necessary recommendations for the prevention of mechanical health hazards. Methods: It is a Cross-Sectional study . The study was conducted from the period of June 2009 to December 2011.. Data Collection: A pilot study was conducted on 10 patients. Data collection was done through asking questionnaire from the patients/relatives(AWs); clinical examination and clinical case records of the patients. Analysis of Data: Data was analyzed in the form of percentage (\%) and presented in the tabular form. Chi- square(X2) test was applied as a test of significance with the help of statistical software SPSS statistics (version- 17) Results: Out of total 53 cases $42(79.25)$ were males and $11(20.75)$ were females. Majority $(75.48 \%)$ of the respondents were hired laborers followed by own land workers $(24.52 \%)$. Males $(79.25 \%)$ were more addicted than females $(20.75 \%)$. Majority of the cases were due to equipment/ instrument induced $(64.15 \%)$, followed by animal induced $(35.85 \%)$ injuries. It was revealed that maximum number of the cases $(83.02 \%)$ were not using PPE and only $16.98 \%$ were using any kind of PPE.
\end{abstract}

Key Words: Agricultural Workers; Personal Protective Equipment; .Health; Risk.

\section{Introduction}

Agriculture is considered to be one of the oldest occupations, perhaps as old as human civilization. Approximately 2 billion people are engaged in agriculture and related work in the developing countries of Asia, whereas the developed countries contribution is merely 100 millions [1]. The incidence, prevalence and the variety of occupational diseases have considerably increased after the industrial revolution. The International Labour Organization (ILO) estimates that there are 120 million occupation related accidents each year, leading to 12 million permanent disabilities. Apart from work-related accidents, workers are also prone to work-related diseases. The WHO estimates that the incidence of occupation related diseases would be in the range of 68 to 157 million new cases per year. About $10 \%$ result in permanent disabilities and about $0.5 \%$ to $1 \%$ deaths [2]. In a country like India, large workforce is employed in diverse settings. Today we have 360 million workforce, of which 225 million in agriculture \& 120 million are in industrial
Vijay Kumar Manwani, Sachin Pandey

Department of Community Medicine, Chhattisgarh Institute of Medical Sciences Sardar Vallabh Bhai Patel Hospital Bilaspur, Chhattisgarh, India

Corresponding Author:

Dr. Vijay Kumar Manwani Email: vkmukm77@gmail.com

○ 2014 IJOSH All rights reserved. sector [3].So, we can conclude that there is a heavy burden of occupational disease in our country and that it has impact on productivity, health and safety. Hence it is imperative to strengthen occupational health [4].

In the last 50 years, due to rapid industrialization, India has been considered as a newly industrialized country. In spite of this $50 \%$ of our Gross Domestic Product is still being contributed by agriculture sector. Thus, this sector is very vital and the most important sector of our economy [5]. In the fourth report of the joint ILO/WHO committee on occupational health, agriculture was taken to mean all forms of activities connected with growing, harvesting and primary processing of all types of crops, with breeding, raising and caring for animals and with tending gardens and nurseries. An agriculture worker means any person engaged either permanently or temporarily, in activities related to agriculture as defined above, irrespective of his/her legal status [6]. In India Ministry of Labour includes ploughing, sowing, weeding, transplanting, harvesting, cultivation, forestry, 
plantation, fisheries, and others as principal agricultural operations [7]. Agriculture is one of the most hazardous occupation worldwide. In several countries the fatal accident rate in agriculture is double the average for all other industries. Out of a total of 3,35,000 fatal workplace accidents worldwide, there are some $1,70,000$ deaths among agricultural workers. The intensive use of machinery and of pesticides and other agro-chemicals has raised the risks. Machinery such as tractors and harvesters has the highest frequency and fatality rates of injury. Available data from developing countries shows that there has been an increase in the accident rate in agriculture. Such accidents occur mainly among migrants and daily workers, as well as women and children. The environment in which farmers work and live, their standard of living and their nutrition are, as important to their health, as the services available to them [8]. India being a country of agriculture, majority of its population is engaged in agriculture based activities in a varied manner either directly or indirectly. This sector of activity being most unorganized, very little attention has been given to the occupational health problems of these workers; though the need of investigation and intervention towards these problems has repeatedly been mentioned [9]. Given the paucity of data, it is hoped that this study will provide answers to the quantum of occupational health and safety (OHS) issues among the agricultural workers and provide guidance on measures, for reducing mechanical health hazards amongst agricultural workers and thus may help in improving the health and well-being of agricultural workers.

\section{Objective}

1. To find out the demographic distribution of agriculture related mechanical health hazards.

2. To find out the magnitude of agriculture related mechanical health hazards.

3. To find out the protective measures being used by the agricultural workers for the prevention of mechanical health hazards.

4. To give the necessary recommendations for the prevention of mechanical health hazards.

\section{Methods}

Study design: It is a Cross-Sectional study. The study was conducted from the period of June 2009 to December 2011.

Study Area: Pravara Rural Hospital of Rural Medical College Loni falls under Ahmednagar District of Western Maharashtra, which is a tertiary care teaching hospital chiefly catering the demands of Ahmednagar and adjacent districts of Maharashtra and thus acts as an apex referral institution. Ahmednagar district has $80.34 \%$ rural population and $19.66 \%$ urban population. Majority of the people in study area are engaged in agricultural activities. Data Collection: A pilot study was conducted on 10 patients. Data collection was done through asking questionnaire from the patients/relatives; clinical examination and clinical case records of the patients.

Analysis of Data: Data was analyzed in the form of percentage (\%) and proportion and presented in the tabular form. Chi- square $(X 2)$ test was applied as a test of significance with the help of statistical software SPSS statistics (version-17).

\section{Results}

Maximum number of patients were males $(42,79.25 \%)$, followed by females $(11,20.75 \%)$. Majority of the patients $(50.95 \%)$ were belonging to age group of $>20$ to 40 years. Males $(39.63 \%)$ were preponderant in the age group of $>20$ to 40 years followed by females $(11.32 \%)$,in the same age group. Male:Female ratio was 3.81:1.Mean age was 31.18 with SD of 12.19. This highlights that majority of the respondents were between age group of 15 to 45 years which is physiologically active and most commonly engaged age group in agricultural activities. It was revealed that majority $(75.48 \%)$ of the respondents were hired laborers followed by own land workers (24.52\%). This may be due to reasons that hired laborers are accountable to land owners and for giving maximum output; which is related to their daily wages, they may work continuously for longer period of time, to earn livelihood which gives fatigue and stress and ultimately predisposes them to various hazards. Secondly land owners employing this hired labors ,may not show concern about use of PPE and giving adequate rest in between work. Thirdly land owners ask them to take risky jobs like spraying pesticides or operations involving machineries. Majority of the patients of agricultural hazards were not using (83.02\%) personal protective equipment's and only $16.98 \%$ were using any kind of PPE (gloves-9.15\%, mask-0.41\%, goggles $0.33 \%$, hat/helmet-01.26\%, gumboots-0.34\%,jacket/apron $2.55 \%$ and using $>1$ PPE $-2.94 \%$ ). It was revealed that majority of the cases of mechanical hazards were due to equipment/instrument induced $(64.15 \%)$, followed by animal induced $(35.85 \%)$ injuries.

Table I Age and Gender wise distribution of cases

\begin{tabular}{|cccc|}
\hline Age group & Male(\%) & Female(\%) & Total(\%) \\
\hline$<20$ & $08(15.09)$ & $02(03.77)$ & $10(18.86)$ \\
$>20-40$ & $21(39.63)$ & $06(11.32)$ & $27(50.95)$ \\
$>40-60$ & $09(16.98)$ & $02(03.77)$ & $11(20.75)$ \\
$>60$ & $04(07.55)$ & $01(01.89)$ & $05(09.44)$ \\
Total & $42(79.25)$ & $11(20.75)$ & $53(100)$ \\
Mean / SD & $31.23 / 12.47$ & $31.12 / 11.75$ & $31.18 / 12.19$ \\
\hline
\end{tabular}

Table II Distribution of cases according to agriculture worker's status

\begin{tabular}{|cccc|}
\hline AWs Status & Male(\%) & Female(\%) & Total(\%) \\
\hline Hired Labourer & $33(62.27)$ & $07(13.21)$ & $40(75.48)$ \\
\hline Own Land Worker & $09(16.98)$ & $04(07.54)$ & $13(24.52)$ \\
\hline Total & $42(79.25)$ & $11(20.75)$ & $53(100)$ \\
\hline
\end{tabular}

Value of $x^{2}=36.783, d f=1, p<0.001$, highly significant 
Fig 1. Pie diagram showing AWs status

worker's status

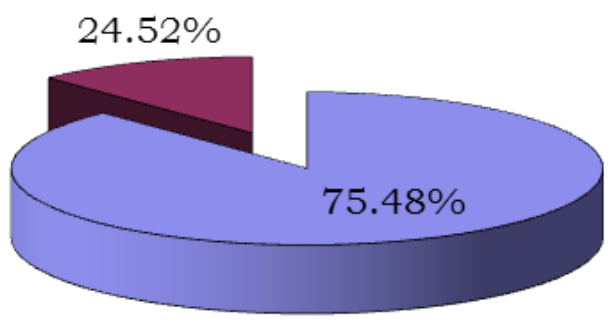

$\square$ hired labourer $\quad$ awn land worker

Table III Addiction pattern of cases

\begin{tabular}{|c|c|c|c|}
\hline Type of addiction & Male(\%) & Female(\%) & Total(\%) \\
\hline None & $01(1.89)$ & $07(13.21)$ & $09(15.10)$ \\
\hline Alcohol & $04(07.55)$ & $00(00)$ & $04(07.55)$ \\
\hline Smoking & $03(05.66)$ & $00(00)$ & $02(05.66)$ \\
\hline Smokeless Tobacco & $18(33.96)$ & $04(07.54)$ & $22(41.50)$ \\
\hline$>1$ (Alcohol +Tobacco) & $16(30.19)$ & $00(00)$ & $16(30.19)$ \\
\hline Total & $42(79.25)$ & $11(20.75)$ & $53(100)$ \\
\hline
\end{tabular}

Value of $\mathrm{x} 2=442.78, \mathrm{df}=4, \mathrm{p}<0.001$, highly significant

By applying chi-square test there was a highly significant between males and females and addiction pattern of patients under study.

Table IV Use of PPE amongst cases of mechanical hazards

\begin{tabular}{|c|c|c|c|}
\hline Use of PPE & Male(\%) & Female(\%) & Total(\%) \\
\hline Not using & $35(66.04)$ & $09(16.98)$ & $40(83.02)$ \\
\hline Using & $07(13.21)$ & $02(03.77)$ & $13(16.98)$ \\
\hline Total & $42(79.25)$ & $11(20.75)$ & $53(100)$ \\
\hline
\end{tabular}

Value of $x 2=7.428, d f=1, p<0.01$, significant

By applying chi-square test there was a significant association between sex-wise distribution of agricultural hazards and use of PPE.

Table V Types of Mechanical hazards

\begin{tabular}{|c|c|c|c|}
\hline Hazard & Male(\%) & Female(\%) & Total(\%) \\
\hline $\begin{array}{c}\text { Equipment/Instrument } \\
\text { induced }\end{array}$ & $29(54.72)$ & $05(09.43)$ & $34(64.15)$ \\
\hline Animal induced & $13(24.53)$ & $06(11.32)$ & $19(35.85)$ \\
\hline Total & $42(79.25)$ & $11(20.75)$ & $53(100)$ \\
\hline
\end{tabular}

Value of $\mathrm{X} 2=2.110, \mathrm{df}=1, \mathrm{p}>0.05$, not significant

By applying chi-square test there was no significant association between males and females and types of mechanical hazards.

\section{Discussion}

In the present study maximum number of patients were males $(42,79.25 \%)$,followed by females $(11,20.75 \%)$. Majority of the patients $(50.95 \%)$ were belonging to age group of $>20$ to 40 years. Our findings were consistent with the findings of A. Saha et al. [9] $(\mathrm{N}=400), 86.25 \%$ were males (mean age $38 y$ rs $+10.7 \mathrm{SD}$ ) and majority in the age group of 30 to 49 years, 7 Kadam Shridhar M et. al.[10] (males - 56.1\%, females-43.9\%, N = 935), comments age group was 26-35 years, Nayak CS et al [11] (males-83.33\%, females-16.67\%,N=138), commonest age group was 21-30 years, Thomas A. Arcury et al. [12] (males$93.2 \%$, females-6.8\%), almost two third were young under 30 years of age, Dimiich Ward H et al. [13] (males-91.48\%, females$8.52 \%, \mathrm{~N}=716$ ), RB Gurav et al. [14] (males-59.72\%, females$40.28 \%, N=288$ ), one third of the respondents were in the age group of 26-40 years, Singh B [15] (males-68.30\%, females$31.70 \%, N=385) 61.8 \%$ of the patients were between 21 to 30 years, G.V. Ranga Rao et al. [16] ( $N=1185$,males-93\%, females$7 \%$ ), and Dilshad Ahmad Khan et al. [17] ( $\mathrm{N}=105$, all males), mean age-26yrs +9 SD Our findings were different from Zhang et al. [18] $(N=910)$ in which they found that $53.1 \%$ cases were females. And Francesca Mancini et al. [19] (males $=47$, females $=50$ ) It was revealed that majority $(75.48 \%$ ) of the respondents were hired laborers followed by own land workers $(24.52 \%)$. These findings were consistent with Thomas A. Arcury et al. [12] (53.1\% hired contract laborers), Francesca Mancini et al. [19] (majority of the workers were farm laborers). Majority of the patients of agricultural hazards were not using $(83.02 \%)$ personal protective equipment's and only $16.98 \%$ were using any kind of PPE. Similar findings were observed by JE Cornwall et al. [20] where they found that majority of the farmers were not using any PPE, while working in the tobacco farms. Nayak CS et al. [11] observed that majority of the workers were not using any protective measures. Subashiny Nagenthirarajah and $\mathrm{S}$. Thiruchelvam [21] observed that only $6 \%$ of the farmers had awareness towards recommended protective measures. G.V. Ranga Rao et al. [16] revealed that $50 \%$ of the farmers in India were not using any PPE.. In the present study majority of the cases of mechanical hazards were due to equipment/instrument induced $(64.15 \%)$, followed by animal induced $(35.85 \%)$ injuries. Similar findings were noted by Verma SR et al. [22] where they found that $73 \%$ of the injuries were due to human factors, $13 \%$ due to machines and equipments, $14 \%$ due to other factors. Zhou C and Roseman JM [23] noted maximum injuries due to machinery $(28.6 \%)$ followed by falls $(23.2 \%)$ and animals (12.5\%), Noba Athikho et al. [24] noted $42.08 \%$ of the injuries due to machines. Dimich Ward $\mathrm{H}$ et al. [13] observed greater number of males were injured (91.48\%) followed by $8.52 \%$ of the females due to farm fatalities. Jonthan $\mathrm{N}$ et al. [25] found maximum number of injuries by equipment's/implements $(52.3 \%)$ followed by animal injuries $(30.7 \%)$. However Nordstrom DL et al. [26] in their study did not show similar findings (animals were the most frequent source of injury). Pranab Kumar NAG and Anjali NAG (2004) [27]: also Studied magnitude of accidents and injuries in Indian Agriculture. 
Most of the fatal accidents resulted from the powered machinery, with the annual fatality rate estimated as 22 per 100,000 farmers. The hand tools related injuries ( $8 \%$ of the total accidents) were non-fatal in nature.

Fig 2. Pie diagram showing use of PPE amongst AWs

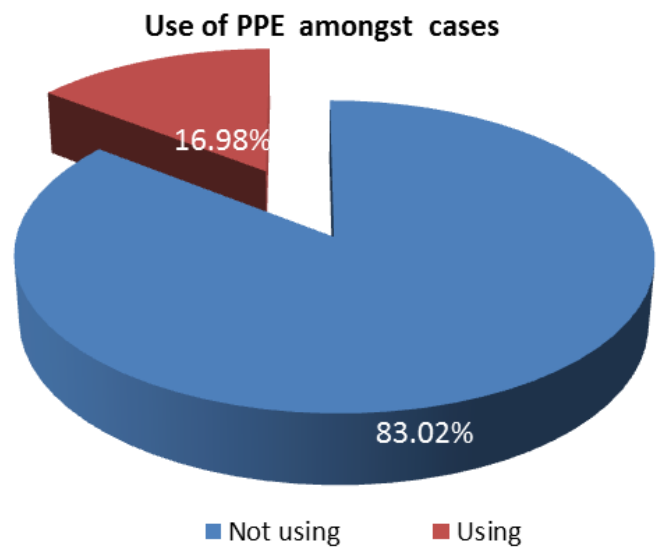

Fig 3. Pie diagram showing Type Of Mechanical Hazards Type of Mechanical hazards

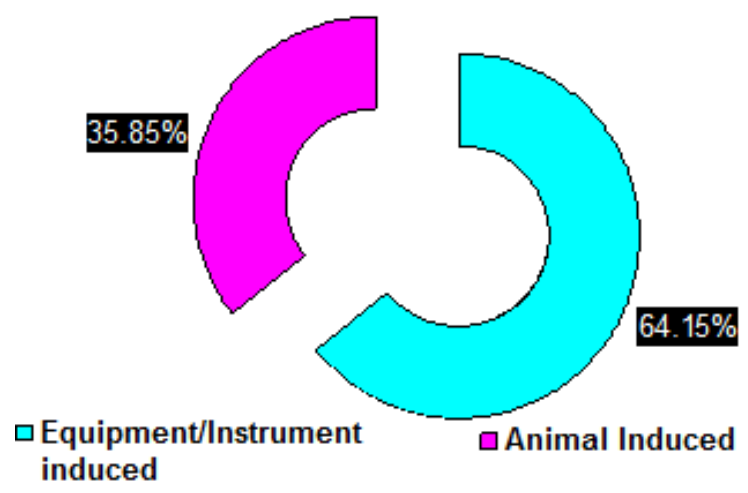

\section{Recommendations}

1. Based on the observations of the present study we suggest following recommendations:

2. In the various agricultural operations, machines older than 20 years, and/or machines with broken static and dynamic structures should be replaced.

3. Careful handling of instruments/ equipment's and animals, can avoid traumatic injuries. The handling of cutting instruments should have a protection guard, to avoid hand slipping on the blade and readiness of first aid facilities to decrease the risk of small injuries becoming serious.

4. The moving parts of the machineries (threshers, chaff cutters etc.) should be fully protected by adequate guards, as to prevent access to them.

5. All personal precautions like wearing proper clothing, wearing gumboots/shoes, while working in the farms are to be taken to prevent occurrence of injuries.

6. Proper equipment's / machines maintenance level: brakes; suspension; tire pressure and general conditions to prevent mechanical hazards.

7. Redesigning of the equipment's, tools and agriculture machineries on the principles of ergonomic to avoid mechanical injuries.
8. Sale of alcohol and tobacco products should be restricted and its use should be discouraged by properly educating the farmers.

9. De-addiction programmes to be organized for addicted farmers.

10. There is need of further exploratory research in direction of early detection, prevention and control of occupational diseases and injuries, amongst agricultural workers.

\section{Conclusion}

In the present study total 53 patients of agriculture related occupational health hazards were studied, out of these 42 (79.25) were males and 11(20.75) were females.

In our study majority of the patients (33.80\%) were belonging to age group of $>20$ to 40 years. Males (39.63\%) were preponderant in the age group of $>20$ to 40 years, followed by females $(11.32 \%)$ in the same age group. Male: Female ratio was 1.81:1. Mean age for the all patients was $31.18+12.19 S D$. Mean age of males was $31.23+12.47 \mathrm{SD}$ and of females was 31.12+11.75SD.

In our study it was observed that majority $(75.48 \%)$ of the respondents were hired laborers followed by own land workers (24.52\%).

Majority $(63.61 \%)$ of the respondents in the present study have some kind of addiction in the form of smokeless tobacco (gutkha, khaini, mishri etc.- 41.50\%) alcohol (7.55\%),smoking(5.66\%) or more than one addictions(30.19\%). Males(79.25\%) were more addicted than females(20.75\%).

It was revealed that majority of the cases of mechanical hazards were due to equipment/ instrument induced (64.15\%), followed by animal induced (35.85\%) injuries.

It was revealed that maximum number of the cases of agricultural hazards were not using $(83.02 \%)$ any personal protective equipment's and only $16.98 \%$ were using any kind of PPE (gloves- $9.15 \%$, mask-0.41\%, goggles- $0.33 \%$, hat $/$ helmet$01.26 \%$, gumboots-0.34\%,jacket/apron-2.55\% and using >1 PPE -2.94\%) .

So from the present study we can conclude that, various types of the mechanical, hazards; are the common agriculture related occupational health hazards which are frequently found amongst the agricultural workers. If these hazards are addressed correctly, can be prevented by simple precautionary and protective measures.

\section{References}

1. R N Chaudhari, "Occupational Health Problems among Agricultural and Plantation Workers": Journal of the Indian Medical Association: 2000; vol. 98(8):439-445.

2. Bharmal NR \& Bharmal RN, "Occupational health: past, present and future": Indian journal of occupational health: 2001; vol. 44 (4): 61-65.

3. Sunderlal-Text book of Community Medicine: CBS Publishers: $1^{\text {st }}$ edition 2007: 7, 8-9.

4. Jugal Kishore -National Health Programs of India: Century Publications: 7th edition: 2007: 621. 
5. Dave Sudhir K, "Occupational Health Services For Agriculture Workers" Indian Journal Of Occupational and Environmental Medicine: 1998; vol.02 (2): 96-111.

6. World Health Organization: "Occupational health problems in agriculture" Technical Report Series No. 246:1962:1-61.

7. Labour Bureau; Indian Labour Year Book; Simla; Ministry of Labour, Government of India: 1996.

8. Safe work, Programme on safety, health and the environment: Labour Protection Department, International Labour Office, ILO year book: 1999; Geneva.

9. A.Saha, D.S.Munda, H.R.Rajmohan "Morbidity of Grain Handling Workers-A Cross Sectional View ": Indian Medical Gazette: 2010; vol. XLIV (10): 387-391.

10. Kadam Shridhar M, Wahab S N, Zodpey S P, Fulare M B "Morbidity Pattern In Agricultural Workers" : Indian Journal Of Occupational Health: 2001:vol. 44 (4): 187-191.

11. 11. Nayak CS, lyer LV, Jerajani HR: "A study of occupational dermatitis in Mumbai": Indian journal of occupational and environmental medicine: 1998; vol.2 (2):88-91.

12. 12. Thomas A. Arcury, Sara A. Quandt, and Gregory B. Russell "Pesticide Safety among Farm workers: Perceived Risk and Perceived Control as Factors Reflecting Environmental Justice" Environ Health Perspective: 2002; vol.110 (suppl-2):233-240.

13. 13. Dimich-Ward H, Guernsey JR, Pickett W, Rennie D, Hartling L, Brison RJ. "Gender differences in the occurrence of farm related injuries" Occup. Environ. Med: 2004; vol. 61(1):52-56.

14. 14.Gurav RB, Kartikeyan S, Wayal R, Joshi SD: "Assessment of health profile of daily wage labourers" Indian J Occup Environ Med 2005; vol.9 (3):115-117.

15. 15. Singh B: "Profile of acute poisoning from agricultural and horticultural chemicals in ICU, at Pravara Rural Medical College, Loni”. Pravara Medical Review: 2006; vol.1 (4):1316.

16. 16. G.V. Ranga Rao, V. Rameshwar Rao, V.P. Prasanth, N.P. Khannal, N.K. Yadav and C.L.L. Gowda "Farmers' perception on plant protection In India and Nepal: a case study" International Journal of Tropical Insect Science: 2009; vol. 29: (3), 158-168.

17. 17. Dilshad Ahmed Khan, Saira Shabbir, Mahwish Majid, Tatheer Alam Naqvi and Farooq Ahmed Khan: "Risk assessment of pesticide exposure on health of Pakistani tobacco farmers": Journal of Exposure Science and Environmental Epidemiology: 2010; vol. 20, 196-204.

18. 18. Zhang $X$, Zhao $W$, Jing $R$, Wheeler $K$, Smith $G A$, Stallones L, Xiang $H_{\text {.: }}$ "Work-related pesticide poisoning among farmers in two villages of Southern China: a cross-sectional survey"; 2011;URL:http://www. biomedcentral.com. assessed on 6 Sep. 2011.

19. 19.Francesca Mancini, Ariena H. C.Van Bruggen, Janice L. S. Jiggins, Arun C. Ambatipudi, Helen Murphy, Acute Pesticide Poisoning among Female and Male Cotton Growers in India: Int. J Occup Environ Health: 2005;vol.11(3):221-232.

20. JE Cornwall, ML Ford, TS Liyanage, D win kyi daw: "Risk assessment and health effects of pesticides used in tobacco farming in Malaysia": Oxford Journals of Medicine Health Policy and Planning: 1995; vol.10 (4): 431-437.

21. Subashiny Nagenthirarajah1 and $S$. Thiruchelvam: "Knowledge of Farmers about Pest Management Practices in Pambaimadu, Vavuniya District: An Ordered Probit Model Approach": Sabaramuwa University Journal: 2008; vol. 8 (1); 79-89.
22. Verma SR, Rawal GS, Bhatia BS: "A study of human injuries in wheat threshers": Indian Journal of Agricultural Engineering: 1978; vol.15:19-23.

23. Zhou C, Roseman JM: "Agricultural injuries among a population-based sample of farm operators in Alabama": American Journal of Industrial Med.: 1994; vol.25 (3):385402

24. Noba Athikho Loli, Poulose Biju, Joseph Bobby: "A profile of accidents reporting to a Rural Plantation Based Hospital": Indian Journal of Occupational and Environmental Medicine: 2000; vol.4 (3):125-127.

25. Jonathan N. Hofmann, Jennifer Crowe, Julie Postma, Vickie Ybarra, Matthew C. Keifer: "Perceptions of Environmental and Occupational Health Hazards among Agricultural Workers in Washington State": AAOHN J.: 2009; vol.57 (9): 359-371:URL:URL:http//www.pubmed.gov.in:assessed on 18 Feb. 2011.

26. Nordstrom DL, Layde PM, Olson KA, Stueland D, Brand L, Follen MA "Incidence of farm-work-related acute injury in a defined population" Am J Ind Med. :1995 ; 28(4):551-64.

27. Pranab Kumar NAG and Anjali NAG: "Drudgery, Accidents and Injuries in Indian Agriculture": Industrial Health: 2004; vol.42, 149-162. 